\title{
An Assessment Of The Performance Of The Different Types Of Biomass (Agricultural) Waste When Used As Fuels In A Gasifier Stove.
}

\author{
Benedictor Waniala ${ }^{a, 1}$, Florence Nassimbwa ${ }^{a}$ \\ a Uganda Martyrs University Nkozi
}

\begin{abstract}
\end{abstract}

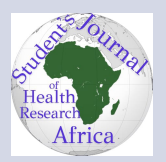

Introduction:

The world is experiencing adverse climatic changes due to the high demand for biomass energy with an increasing population. Many forests are being cut down to meet the biomass energy demand. A lot of research to identify alternative fuels especially from agricultural waste is being tried. Pinewood, pine cones, maize cobs, and wood shavings are among the fuels that are regarded as a waste but can be used in a gasifier stove as alternative fuels amidst the depleting forests.

Methodology:

The study was conducted from the Biomass Resource and Training Center of Nyabyeya Forestry College located in Masindi near Budongo Forest, Uganda. From the results, Wood shavings had the lowest specific fuel consumption of $90 \mathrm{~g} / \mathrm{liter}$ as compared to pine wood with $101 \mathrm{~g} / \mathrm{liter}$, maize cobs with $103 \mathrm{~g} /$ liter, and pine cones with the highest of 107g/liter.

Results:

Maize cobs were found to be a better alternative fuel for the gasifier stove use, this is because, their time to boil 2.5 liters of water is about 12 minutes, the burning rate is $20 \mathrm{~g} / \mathrm{min}$, the specific fuel consumption was about $104 \mathrm{~g} / \mathrm{liter}$ and had the best thermal efficiency of about 33\% with the specific gasifier stove.

\section{Recommendation:}

Maize cobs are recommended for use in the gasifier stoves, apart from the scientific evidence, maize cobs have other benefits associated with their wide availability and cheap or no cost since they exist as agricultural wastes, this would help in reducing the pressure on forests for wood fuels like charcoal and firewood.

Conclusion: ${ }^{a}$

Pine cones had the lowest time to boil of 9.5 minutes compared to maize cobs with 12.25 minutes and pinewood with the highest which was 13.25 minutes.

\footnotetext{
${ }^{a}$ Date submitted: $10^{\text {th }} / 11 / 2021$ Date accepted: 13 th $/ 11 / 2021$ Email: wbenedictor@gmail.com
}

\section{Background}

About 2.4 billion people use traditional biomass for cooking, either wood, crop residues, charcoal, or animal waste (Biomass for heating | Climate Technology Centre \& Network | Tue, 11/08/2016, no date). It is also believed that an extra 200 million peo- 
ple worldwide will rely on biomass for their cooking and heating needs by 2030 (Biomass for heating | Climate Technology Centre \& Network | Tue, 11/08/2016, no date). Biomass energy is of great interest for global development (Ariho, Tumutegyereize and Bechtel, no date).

According to FAO 2016, in rural areas as far as Africa is concerned, $98 \%$ of the population rely on biomass as a major source of energy for cooking and lighting, this can be obtained as wood fuel, charcoal, Biogas, Briquettes, and many others.

Introduction: Uganda has a total primary energy consumption of 0.0593 quadrillion Btu which equals 14.94 Mio. Tons of oil equivalent Between 1999 and 2018, the primary energy consumption of Uganda grew substantially from 0.03 to 0.1 quadrillion but rising at an increasing annual rate that reached a maximum of $21.32 \%$ in 2000 and then decreased to $-4.48 \%$ in 2018 (Uganda - World - Consumption - Primary Energy - knoema.com, no date), (U.S. Energy Information Administration -( ht tp://www.eia.gov accessed 4th 04 2021)) Biomass is still the most important source of energy for the majority of the population. Biomass is the predominant type of energy used in Uganda, accounting for $94 \%$ of the total energy consumption in the country ('Overview of the Ugandan Energy Sector | Uganda National Renewable Energy \& Energy Efficiency Alliance (UNREEEA)', no date). It is used for energy mainly in two forms; firewood and charcoal and its total primary energy consumption is generated through biomass can be separated in firewood (78.6\%), charcoal (5.6\%), and crop residues (4.7\%). According to African review 03 November 2011, Current figures indicate that charcoal consumption in Kampala is estimated at 205,852 tonnes per year with an increase of six percent annually while countrywide, charcoal consumption is put at 723,014 tonnes annually (Thomson, no date). This confirms that Charcoal consumption increases at a rate of $6 \%$ per annum. Heavy dependence on wood and charcoal has resulted in deforestation hence stimulating the need to use alternative biomass resources as fuels especially from agricultural waste. Some of the examples of these biomass resources include maize cobs, wood shavings, pine cones, and wood pieces. However, apart from wood, the rest have hardly been used for cooking due to the lack of an appropriate technology to obtain energy from them.

The technology to burn these fuels results in poor combustion efficiency and high levels of in- door air pollution which is estimated that over 3.8 million people a year die prematurely from illness attributable to the household air pollution caused by the inefficient use of solid fuels and kerosene for cooking (Smarter cooking technology for better living, no date). Among these 3.8 million deaths, $27 \%$ are due to pneumonia, $18 \%$ from stroke, $27 \%$ from ischaemic heart disease, $20 \%$ from chronic obstructive pulmonary disease (COPD), $8 \%$ from lung cancer (ISO - Smarter cooking technology for better living, no date).

Respirable particulates (small particles of smoke that get into the lungs) are considered to be the most dangerous and carbon monoxide is another known hazard in 2013, particulate matter was classified as a cause of lung cancer by WHO's International Agency for Research on Cancer (IARC)(Household air pollution and health, no date).

According to UBOS, 2010, In 2009/2010, 69.1\% used three-stone fire for cooking, $18.5 \%$ used traditional charcoal stoves, $8.5 \%$ used improved stoves, $1.1 \%$ used paraffin stove and $2.8 \%$ used others.

Therefore, one of the ways through which alternative fuels can be used to obtain energy from them with less pollution while meeting the cooking and heating needs of people is by using the gasifier stoves in which different types of biomass resource materials can be used.

Gasification of biomass is a cleaner, more efficient, and more convenient cooking option than the direct combustion of biomass. Gasifier stoves appear to be promising for community-type cooking as these stoves can be designed to offer high heat power, and produce very little smoke. A gasifier stove is an interesting option to address the problem of smoking in the case of conventional biomass-fired stoves (Pitaksa S. and Prapaporn S., 2006).

According to (Biomass for heating | Climate Technology Centre \& Network | Tue, 11/08/2016, no date b) In this way, the gasifier stove works by a hightemperature conversion process of solid biomass fuel in a restricted oxygen environment to a mixture of carbon monoxide, hydrogen, and methane which are combustible gases that are burnt by the gasifier stove to produce heat for cooking and boiling water.

This research therefore will compare the performance of different agricultural (biomass) waste which are maize cobs, pine cones, wood shavings, 
and wood pieces as used in the gasifier stove, since they are abundant and can be obtained easily with less cost compared to charcoal which is expensive to buy and recommend the best fuel to be used in a gasifier stove for cooking and heating needs.

The growing population of Uganda is directly proportional to an increase in the energy and employment demand because people have to cook in everyday life (National development plan 3) However, the energy demand entails more emissions and means more people will be vulnerable to climaterelated impacts. The commonly discovered fuels for use in Uganda are forest fuels especially wood compromising fuels from agricultural waste.

In Uganda, biomass is used as a fuel for energy mainly in two forms; firewood and charcoal (government of Uganda statistics like National Household Surveys). These fuels are being utilized using the traditional 3-stone stove as for firewood and traditional metal stove as for charcoal. Many people in developing countries especially those living in urban areas use charcoal stoves for cooking. Though convenient, adaptable, portable, and easy to use, charcoal stoves consume a lot of fuel and large amounts of trees are needed to carbonize wood, hence charcoal stoves have a very big impact on the country's natural forests. The stoves also consume a lot of fuel and emit a lot of pollutants during use.

This research, therefore, is aimed at comparing the performance of the different types of biomass fuels which include pine cones, wood pieces, wood shavings, and maize cobs in a gasifier stove which is designed to use different types of biomass fuels thereby reducing the need to rely on only wood.

In rural Uganda agricultural by-products can be found everywhere. This gives the potential of a significant number of rural households with effective and efficient wood fuel and charcoal replacement.

In addition, the gasifier technology which is relevant for rural Uganda can be made out of scrap metal and can therefore be easy and cheap to produce and repair. (CREEC, 2011).

\section{METHODOLOGY}

\section{Study location}

The experiments were performed from the Biomass Energy Resource and Training Centre (BERTC) at Nyabyeya Forestry College. Nyabyeya Forestry College is located on the fringes of the vast Budongo Forest, $32 \mathrm{~km}$ from Masindi Town on Masindi-Butiaba Road and 246km from Kampala.

\section{Study fuel types \\ Fuel collection and preparation}

Considering wood shavings, maize cobs, wood pieces and pine cones, each of the four mentioned types has specific burning characteristics in the gasifier stove. The fuels were obtained from the college premises and the surrounding communities.

Wood shavings were obtained from the carpentry workshop located inside the college and dried inside the workshop for four weeks and after they were stored.

Maize cobs were got from the surrounding community after the native people living in that area had harvested their maize. They were dried under a drying racket with a translucent roof for six weeks before storing them in the workshop.

Wood pieces from pine tree species were got from the sawmill, the bark was removed and split further more into smaller pieces for quicker drying and the drying process took three weeks in the same drying racket and after they were also stored in the workshop.

Pine cones were got from inside the college after students had dried them to obtain the pine seeds from them. They were further dried for more than two weeks in the same drying racket and after they were stored in the workshop.

The average sizes of the fuels were:

a. The pine cones had an average base diameter of $4.1 \mathrm{~cm}$ and height of $4.4 \mathrm{~cm}$

b. The pinewood had an average length of $7 \mathrm{~cm}$ and a width of $1.8 \mathrm{~cm}$

c. The maize cobs had an average length of 7.2 $\mathrm{cm}$ and a diameter of $1.9 \mathrm{~cm}$

\subsection{Wood shavings had an average thickness of $06 \mathrm{~mm}$}

Tools and materials used during the carrying out of the experiment Table 1: Tools and materials used in the experiments

\section{The gasifier stove}

A natural draft 'Mwoto gasifier' stove was used for conducting the tests which are readily available at the Biomass Energy Resource and Training Center.

It is metallic and cylindrical. The air necessary for combustion enters the stove by the natural draft process. 

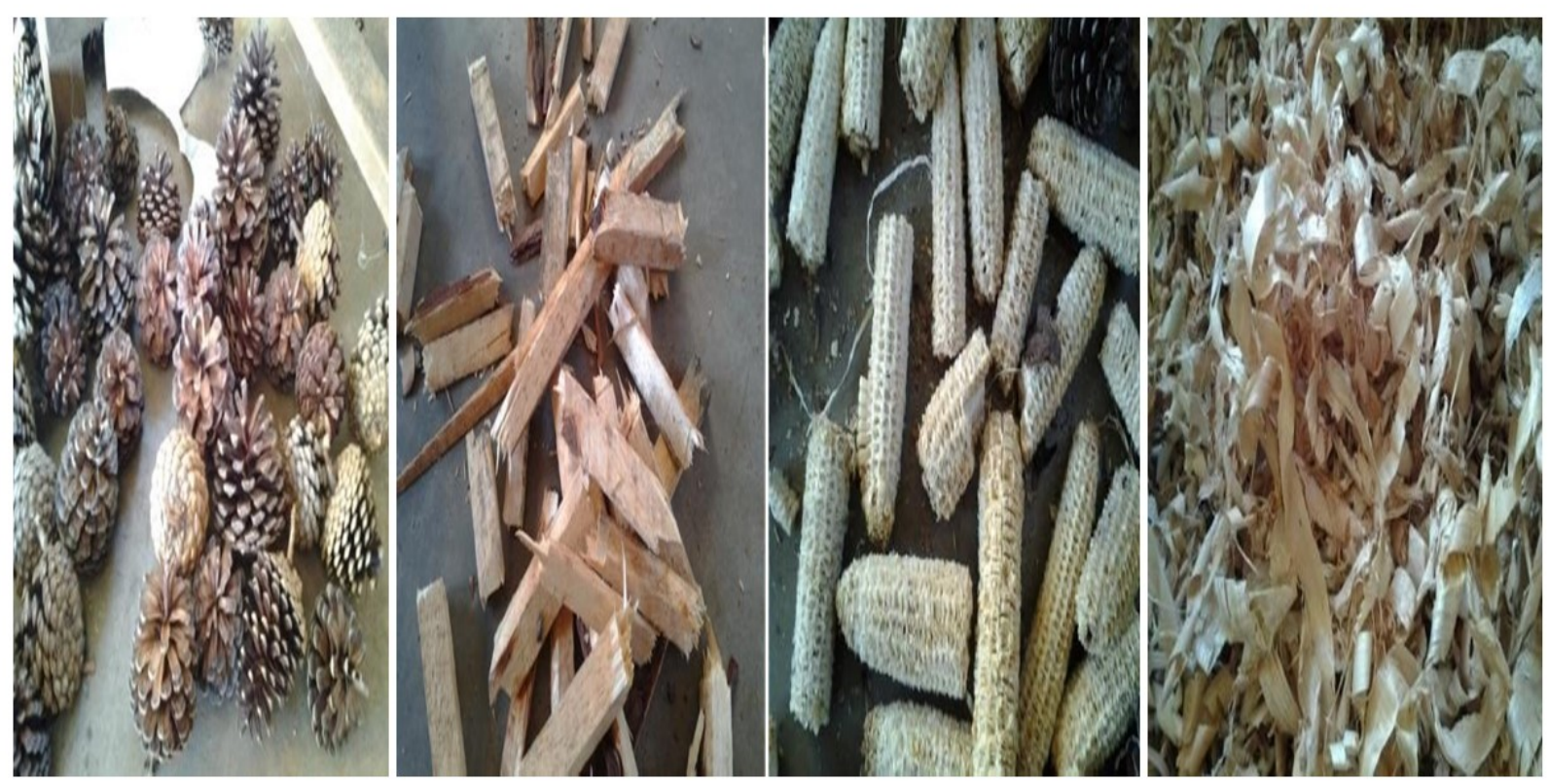

Figure 1. Study fuel types i.e. pine cones, wood pieces, maize cobs and wood shavings respectively

Table 1. Tools and materials used in the experiments

\section{Tools/Materials}

Thermometer Pot/sauce pan Gasifier stove Kerosene Electronic weighing scale $500 \mathrm{ml}$ measuring cylinder Stop watch

Tape measure and a ruler

\section{Purposes}

For reading temperatures Where 2.5 liters of water were boiled from Where the different fuel types will be burnt from For starting the fire For taking weight measurements For measuring water volumes required For recording time taken in each experiment For taking length measurements
It has a cylindrical charcoal container/fuel/combustion chamber which contains a rectangular primary air inlet and also contains a grate with perforations through which the air from the primary inlet passes to reach the fuel in the combustion chamber and it's also where the formed ash of the combusted fuel falls through. The primary air goes through the biomass in the combustion chamber and supports the process of pyrolysis that leads to the release of combustible gases.

It has a cylindrical metallic outer body in which the combustion chamber fits and it also contains a rectangular secondary air inlet where the secondary air passes to provide the oxygen for the burning of the combustible gases. Both air flows combine at the top of the combustion chamber where the combustion takes place to produce heat.
The gasifier stove has three stands that are riveted on the bottom part of the outer body. It has also two handles used for lifting the stove from one place to another. The outer body also contains a removable concentrator lid which contains three riveted pot seats and two circular cavities i.e. one at its top and the other at its bottom through which the flame from the fuel is focused to reach the pot. It's removed when putting the fuel in the combustion chamber and put back for the pot to sit on when boiling the water.

It has a straight piece of metal that has a hook at one end for lifting out the combustion chamber from the outer body when it is still hot just after finishing the experiment. 

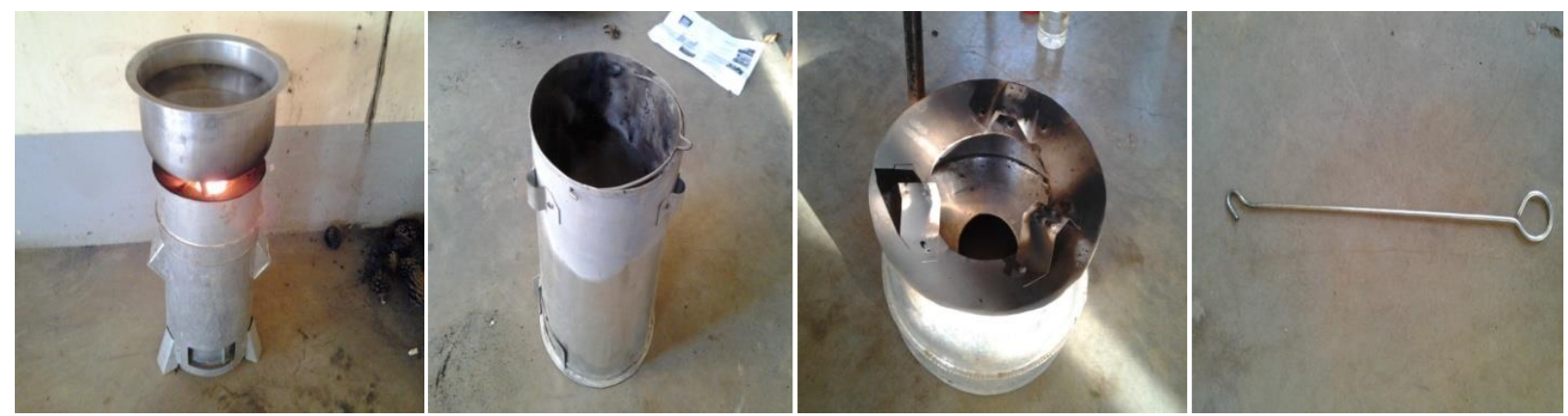

Figure 2. Gasifier stove, combustion/fuel chamber, concentrator lid and hook ended metal respectively

Table 2. Gasifier stove components and dimensions

\begin{tabular}{llll}
\hline Component & Dimensions & Units & Quantity \\
Empty stove & Weight & $\mathrm{g}$ & 3714 \\
Combustion chamber & Weight & $\mathrm{g}$ & 1270 \\
Perforations in the grate & & & 28 \\
Individual perforation in the grate & Diameter & $\mathrm{cm}$ & 0.9 \\
Primary air inlet & L*H & $\mathrm{cm}$ & $8 * 1.5$ \\
Secondary air inlet & L*H & $\mathrm{cm}$ & $12 * 5$ \\
Combustion chamber & Diameter & $\mathrm{cm}$ & 18 \\
Outer body & Diameter & $\mathrm{cm}$ & 22 \\
Top cavity on the concentrator lid & Diameter & $\mathrm{cm}$ & 13 \\
Bottom cavity on the concentrator lid & Diameter & $\mathrm{cm}$ & 7 \\
Outer body & Height & $\mathrm{cm}$ & 31 \\
Combustion chamber & Height & $\mathrm{cm}$ & 28 \\
Concentrator lid & Height & $\mathrm{cm}$ & 12.5 \\
Pot seats & H*W & $\mathrm{cm}$ & $2.5 * 2$ \\
Stove stands & L*H & $\mathrm{cm}$ & $4 * 2.5$ \\
\hline
\end{tabular}

\section{Gasifier stove components}

For stove stands, $\mathrm{H}$ was measured from the ground level to the stove bottom.

Other measurements were:

Weight of empty stove $(\mathrm{g})=3714$

Overall stove height including its stands and pot seats $(\mathrm{cm})=45$

\section{The electronic weighing scale}

It is used for measuring and recording the weights of some items in some of the steps in the procedures of the Water Boiling Tests.

It has an accuracy of $0.1 \mathrm{~g}$ and during measurement of weights for hot objects in the experiment like pot + hot water, a rectangular wooden piece is placed on top of the metallic scale surface to protect it from getting damaged by the heat from the hot objects being measured.

\section{The pot/saucepan}

A seven-liter saucepan/pot was used for boiling the water. Before starting the next experiment, the soot which had collected on it has to be cleaned off using sand and water to prevent it from accumulating on the pot.

Removing the soot helps to increase the pot's thermal conduction properties of the heat from the gasifier stove which soot would act as an insulator of heat from the stove flame to the water being boiled if left to accumulate on the pot.

Testing Protocol: The Water Boiling Test (WBT)

The Water Boiling Test (WBT) is a simplified simulation of the cooking process. It is intended to measure how efficiently a stove uses fuel to heat water in a cooking pot and the number of emissions produced while cooking. (Source: Water Boiling Test, version 4.2.3)

The Water Boiling Test provides reliable information about the performances of the different fuel 


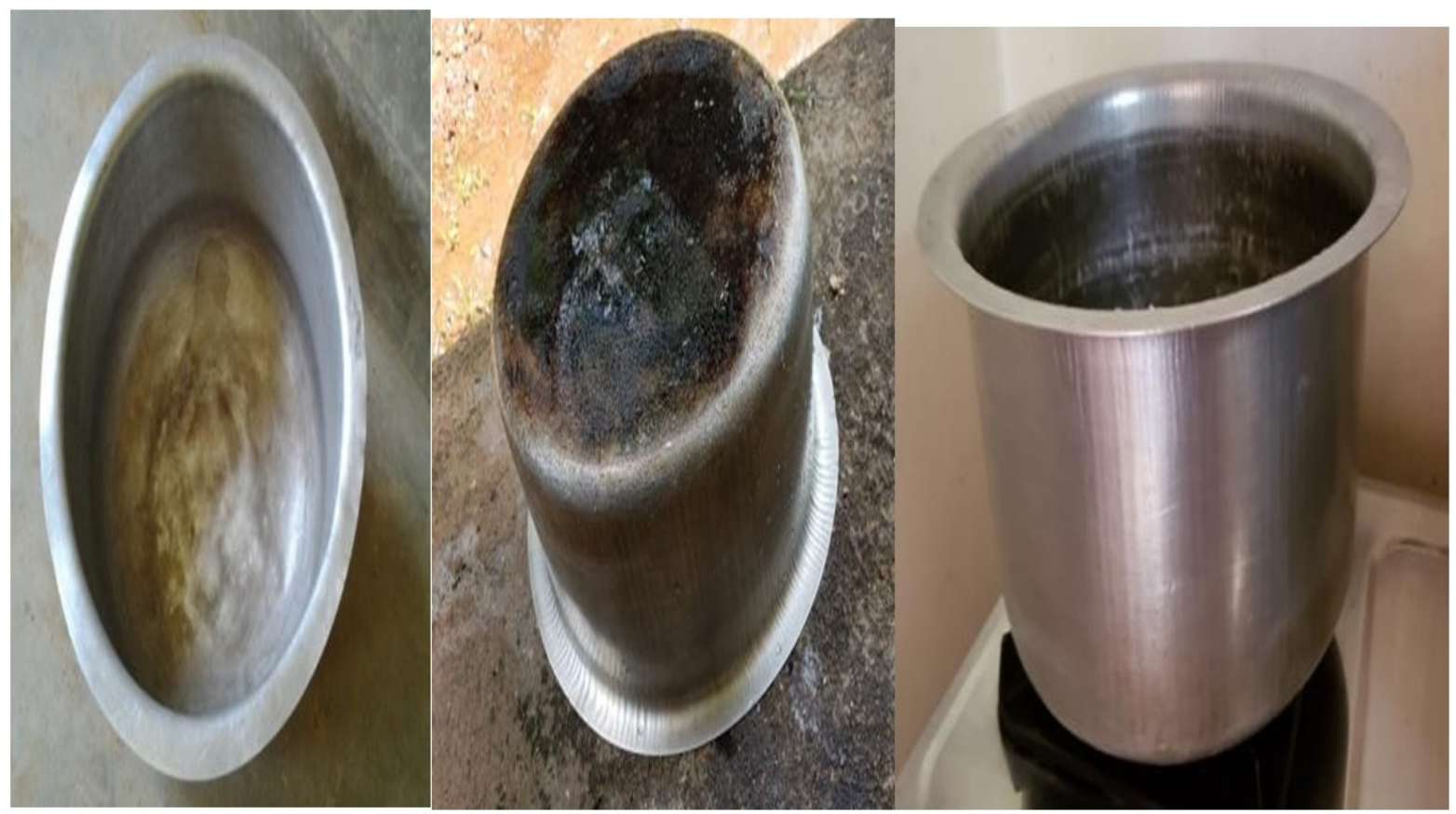

Figure 3. 5: 7-liter pot/saucepan

types by standardizing as many variables such as fuel consumed, time is taken for the water to boil, burning rate and the thermal efficiency of the gasifier stove both at high and low power.

The Water Boiling Test was developed to assess stove performance in a controlled manner, and thus it is probably less like local cooking than other tests described below. Although the WBT is a useful tool for the reasons given below, it's important to remember its limitations. It is an approximation of the cooking process and is conducted in controlled conditions by trained technicians. Laboratory test results might differ from results obtained when cooking real foods with local fuels, even if efficiency and emissions were measured in the same way for both tests. To confirm desired impacts (whether it is fuel conservation, smoke reduction, or other impacts), stoves must be measured under real conditions of use). (Source: Water Boiling Test, version 4.2.3)

The WBT consists of three phases that immediately follow each other. These are shown below. The entire WBT should be conducted at least three times for each fuel, which constitutes a WBT test set.

For the cold-start high-power phase, the tester begins with the stove at room temperature and uses fuel from a pre-weighed bundle of fuel to boil a measured quantity of water in a standard pot. The tester then replaces the boiled water with a fresh pot of ambient-temperature water to perform the second phase.

The hot-start high-power phase is conducted after the first phase while the stove is still hot. Again, the tester uses fuel from a pre-weighed bundle of fuel to boil a measured quantity of water in a standard pot. Repeating the test with a hot stove helps to identify differences in performance between a stove when it is cold and when it is hot. This is particularly important for stoves with high thermal mass, since these stoves may be kept warm in practice.

The simmer phase provides the amount of fuel required to simmer a measured amount of water at just below boiling point for 45 minutes. This step simulates the long cooking of legumes or pulses common throughout much of the world.

A full stove test should always include all three test phases. A quick test for a laboratory's internal use may include only the cold-start and simmer phases if the stove has low mass (no ceramic) and previous WBTs have shown that the cold-start and hot-start phases produce the same results. (Source: Water Boiling Test, version 4.2.3) 
The Water Boiling Test (WBT) version 4.2.3 provides additional guidelines and procedures to follow when carrying out the WBTs on stoves.

\section{Testing Procedures}

The procedure of determining the moisture content of the fuels

Four samples of each of the four fuel types are weighed before putting them in the oven maintained at a temperature of 105 degrees celicius and left there for 18 hours. After 18 hours, the samples are removed from the oven and reweighed to obtain their weight after the water vapour in the fuels has evaporated out.

The moisture content is calculated from the formulae below:

$$
\mathrm{M} . \mathrm{C}=(\mathrm{Mw}-\mathrm{Mo}) / \mathrm{Mw} \text { Where; }
$$

\section{Is the moisture content of the fuel on a wet basis}

Mw is the mass of the wet sample of the fuel weighed before putting it in the oven

Mo is the mass of the dried sample of the fuel weighed after removing it from the oven

The moisture contents of each of the four samples for each fuel type are calculated and the averages of those four samples for each of the fuel types are calculated to obtain one final moisture content value for each of the fuel types.

Testing procedures followed when conducting the Water Boiling Test

\section{High Power (Cold start phase)}

At the start of the experiment, various parameters were recorded and these included; the testing date, the name of the testing fuel, quantity and its dimensions, moisture content, the weight of the empty gasifier stove, the empty charcoal container (fuel/combustion chamber), the amount of lighting material (paraffin) and weight of the empty pot/saucepan.

After taking all the above records, the preweighed test fuel was put into the combustion chamber which in turn was put into the outer body of the gasifier stove and the stove was lit. and 2.5 liters of water at room temperature were measured, poured into the pot (saucepan) and the content was put on the stove, then immediately a stopwatch was started. The stopwatch was stopped as soon as the water reached its boiling point, the temperature read and recorded, and the pot with the boiled water was immediately weighed. The fire in the gasifier stove was put off and the unburnt test fuel and the carbonized fuel (charcoal) formed was sorted out from the uncarbonized (unburnt/partly burnt) test fuel and weighed. The weight was obtained by putting the charcoal in a container which was all initially weighed and the weight obtained was subtracted from the recorded weight of the container.

In case the flame/ fire went off or the test fuel got used up before the boiling point of the test water was reached, the temperature and the time at that point were read and noted, pot with the hot water weighed immediately, this is because the gasifier is a batch fed design and another batch of fuel cannot be added in the combustion chamber during the test in case the initial fuel burns out, this would bring about a reduction in water temperature hence compromising the results.

During temperature reading, the thermometer was placed vertically at about $5 \mathrm{~cm}$ from the bottom of the pot because the temperature of the bottom surface of the pot may be higher than that of the water in the pot since it receives the heat directly from the gasifier stove.

After the above test, another test referred to as the hot start is started; it involves all the steps as above with fresh water.

\section{Low Power (Simmer phase)}

For this experiment, it was a continuation of the hot star. During this phase, the temperature of the water was maintained between $950 \mathrm{C} \pm 30 \mathrm{c}$ for 45 minutes by opening the air inlet to about $0.5 \mathrm{~cm}$ in case the flame was going off before the $45 \mathrm{~min}$ utes elapsed. After this time, the temperature was noted and the pot with the water was immediately weighed.

In case the fire went off or the test fuel got used up before the 45 minutes elapsed, or the water temperature went dropped by six degrees below its boiling point, the experiment was stopped, the temperature and the time at that point were noted and the pot with the water was weighed immediately.

The performance metrics used for comparison of the fuel types.

\section{Burning rate (BR):}

This is a measure of the rate of fuel consumption while bringing water to a boil. It was calculated using the formula below;

rning rat $=$ Averagetotalfuelconsumed $(g) /$ Total time taken ( $\mathrm{min}$ ) 


\section{Specific fuel consumption (SFC):}

This is a measure of the amount of fuel required to boil (or simmer) 1 liter of water. It was calculated using the formula below;

$\boldsymbol{C}=$ Averagetotalfuelconsumed $(\mathrm{g}) /$ Total amount of water (liters)

\section{Thermal efficiency $(\eta)$ :}

Thermal efficiency is a measure of the fraction of heat produced by the fuel that made it directly to the water in the pot. It was calculated using the formula below;

$\eta=$ Energy captured by water/Energy supplied by fuel

\section{Data analysis}

Measurements from the WBT were recorded in the Excel workbook titled WBT_datacalculation_sheet_4.2.3.xls.

This document assumed that the Excel spreadsheet was used. It indicated the sheets within the spreadsheet where the data was entered.

These sheets contained data that was used for calculations throughout the spreadsheet.

Analysis of the results for the data entered in the WBT_data-calculation_sheet_4.2.3.xls was performed on the selected fuel types using both ANOVA test and the T-test.

\section{RESULTS, ANALYSIS AND DISCUSSION.}

The results obtained after several tests on each fuel in the same stove were analysed and discussed as below.

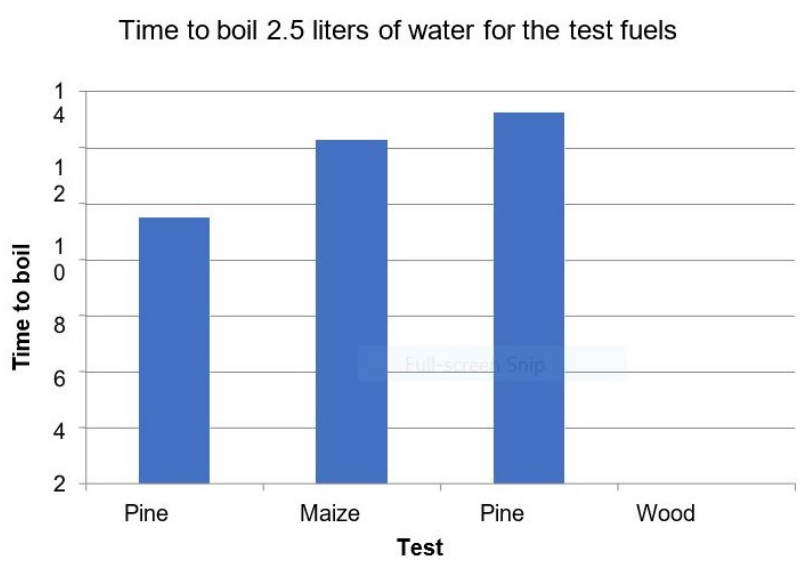

\section{Time to boil}

From figure above, pine cones had the lowest time to boil of 9.5 minutes and pinewood had the highest time to boil of 13.25 minutes. This shows that pine cones absorbed more energy per unit time in the gasifier stove as compared to maize cobs and pine wood. Wood shavings did not boil water because all the fuel fed in the gasifier combustion chamber burnt out and the design of the stove doesn't provide the addition of fuel during operation. However, they heated water to $79^{\circ} \mathrm{C}$ in 7.5 minutes. According to JB/CB, 2011 findings and explanation about the effects of fuel density on heat release rate (HRR), the difference between boiling times of different fuels was attributed to the fact that the fuels with high bulk densities have a low heat release rate compared to those with low bulk density, this makes pine cones and maize cobs boil the water first compared to pine wood.

Table 3: ANOVA for time to boil for three test fuels which raised water to its boiling temperature

From the ANOVA single factor Test, the p-value obtained was 0.0000949 and this was less than the alpha-value of 0.05 , this implies that the differences obtained in the time to boil were statistically significant at $95 \%$ confidence level.the figure below.

\section{Burning rate}

Time to boil 2.5 liters of water for the test fuels

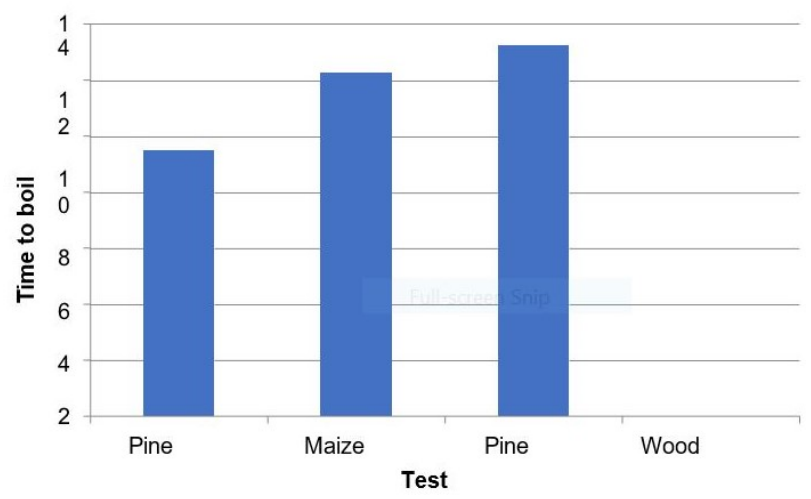

\section{Burning rates of test fuels}

From figure above, pine cones had the highest burning rate of $27 \mathrm{~g} / \mathrm{min}$ compared to wood shavings which had $23 \mathrm{~g} / \mathrm{min}$, maize cobs which had $20 \mathrm{~g} / \mathrm{min}$, and pinewood which had the lowest of 18g/min. According to Mark et al.,(2019), he explained that the higher the bulk density of fuel 
Table 3. ANOVA for time to boil for three test fuels which raised water to its boiling temperature

\begin{tabular}{lllllll}
\hline Source of Variation & SS & df & MS & F & P-value & F crit \\
Between Groups & 30.16667 & 2 & 15.08333 & 54.3 & 0.00000949 & 4.256495 \\
Within Groups & 2.5 & 9 & 0.277778 & & & \\
Total & 32.66667 & 11 & & & & \\
\hline
\end{tabular}

the lower the burning rate, and vise versa was true. Therefore, according to figure 9 above, the pinewood has a high bulk density compared to the other fuels and that is why it took more grams to burn in a minute.

The results for burning rate were analyzed using the ANOVA that was performed on the data at 95\% confidence level and to find out if the difference was significant for each pair of fuel, multiple T-tests were conducted as shown in the table below;

Table 4: Summary of results and conclusions for T-tests performed on burning rates for paired test fuels

From table, Since all the p-values are less than 0.05 , there is a significant difference in the burning rates for each pair of fuel. The highest burning rate of the pine cones is attributed to its open structure which provided a larger surface area for burning as compared to the rest of the test fuels.

Ariho, D et al., (2010) also noted that "burning rate is affected by the bulk density of the biomass fuel. He stated, "the lower the bulk density of the biomass fuel in the "Champion-2008" TLUD gasifier stove the higher the burning rate and vice versa.," He reported this when he compared Jatropha seeds, eucalyptus wood, maize cobs, papyrus, and spear grass of decreasing bulk density respectively in the Champion-2008" TLUD gasifier stove.

\section{Specific fuel consumption}

The test fuels had different specific fuel consumption as shown in the figure below.

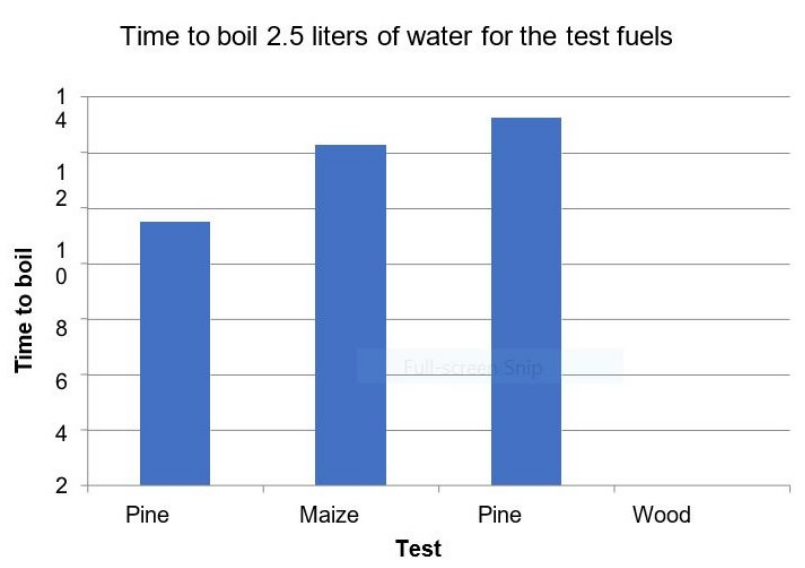

From figure, pine cones had the highest specific fuel consumption of $107 \mathrm{~g} /$ liter, followed by maize cobs with $103 \mathrm{~g} /$ liter, pine wood with $101 \mathrm{~g} /$ liter and wood shavings had the lowest of $90 \mathrm{~g} / \mathrm{liter}$.

The results for specific fuel consumption were analyzed using the ANOVA that was performed on the data at $95 \%$ confidence level as shown in the table below.

From the ANOVA, the p-value is 0.000 and is less than 0.05 which implies that the differences obtained in the specific fuel consumption were statistically significant at a $95 \%$ confidence level.

However, multiple T-tests were conducted to find out if the difference was significant for each pair of fuels as shown in the table below;

Since most of the $p$-values are less than 0.05 except 0.065 for pine cones compared with maize cobs and 0.254 for maize cobs compared with pine wood, there is a significant difference in the specific fuel consumption for the rest of the pairs of fuel.

Since the P-values for pine cones compared with maize cobs and for maize cobs compared with pine wood are greater than 0.05 , it implies that there was no significant difference in specific fuel consumption for the above-stated pairs of fuels. The highest specific fuel consumption of the pine cones is attributed to their low bulk density as compared to the rest of the test fuels. 
Table 4. Summary of results and conclusions for T-tests performed on burning rates for paired test fuels

\begin{tabular}{llll}
\hline Fuels & & T-test P-Value & Significance at 95\% Confidence Level \\
Pine cones & Maize cobs & 0.00024861 & Yes \\
& Wood shavings & 0.010120048 & Yes \\
& Pine wood & 0.0000937424 & Yes \\
Maize cobs & Pine wood & 0.011897876 & Yes \\
& Wood shavings & 0.021347282 & Yes \\
Pine wood & Wood shavings & 0.002626523 & Yes \\
\hline
\end{tabular}

Table 5. Summary of results and conclusions for T-tests performed on specific fuel consumption for paired test fuels

\begin{tabular}{llll}
\hline Fuels & & T-test P-Value & Significance at Confidence Level \\
Pine cones & Maize cobs & 0.064809999 & No \\
& Wood shavings & 0.000156306 & Yes \\
& Pine wood & 0.006526255 & Yes \\
\multirow{2}{*}{ Maize cobs } & Pine wood & 0.25491593 & No \\
\hline
\end{tabular}

Table 6. Summary of resultsand conclusions for T-tests performed on specific fuel consumption for pairedtest fuels

\begin{tabular}{llll}
\hline & Wood shavings & 0.001906111 & Yes \\
Pine wood & Wood shavings & 0.005636623 & Yes \\
\hline
\end{tabular}

Ariho, D et al., (2010) also noted that "Specific fuel consumption is inversely proportional to the bulk density of the biomass fuel. The higher the bulk density of the biomass fuel the lower the specific fuel consumption and vice versa," as he reported when he compared jatropha seeds, eucalyptus wood, maize cobs, papyrus and spear grass of decreasing bulk density respectively

\subsection{Thermal efficiency}

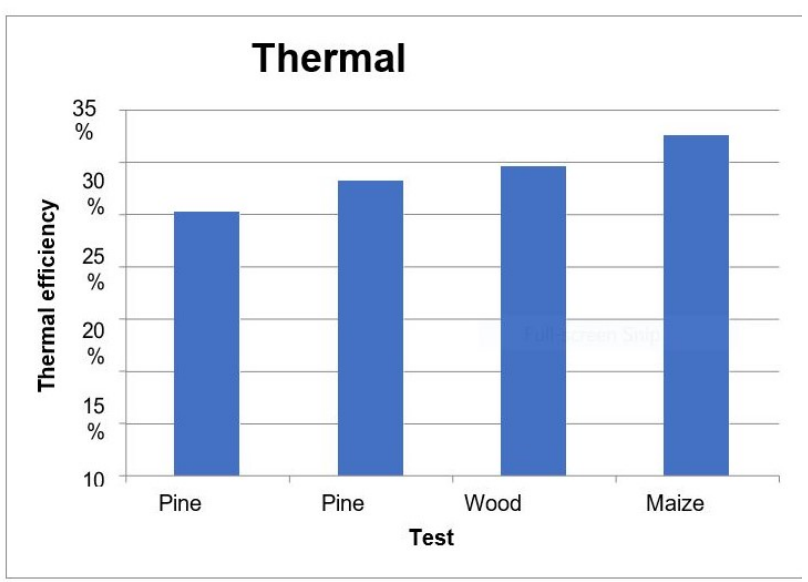

Figure 10: Stove thermal efficiencies with the test fuels

The different test fuels had varying thermal efficiencies with the gasifier stove used as shown in the figure below. Figure 10: Stove thermal efficiencies with the test fuels

From figure above, the stove had the highest thermal efficiency of $32.5 \%$ with maize cobs, followed by wood shavings with $29.6 \%$, pine cones 
with $28.2 \%$ and it had the lowest of $25.2 \%$ with pine wood.

The above results were analyzed using the ANOVA that was performed on the data at 95\% confidence level.

Summary of results and conclusions for T-tests performed on the stove thermal efficiencies for paired test fuels

From the ANOVA in Table above, the average $p$ value is 0.01 and is less than 0.05 which implies that the differences obtained in the thermal efficiencies were statistically significant at a 95\% confidence level.

However, multiple T-tests were conducted to find out if the difference was significant for each pair of fuels as shown in table;

Since most of the p-values are less than 0.05 except 0.121 for pine cones compared with wood shavings, there is a significant difference in the stove thermal efficiencies for the rest of the pairs of fuel.

Since the P-value for pine cones compared with wood shavings is greater than 0.05 , it implies that there was no significant difference in the stove thermal efficiencies for the above-stated pair of fuels.

The factor that could have influenced the results:

The size and shape of the fuel influenced the primary airflow throughout the entire fuel in the combustion chamber thereby affecting the combustion reaction of the fuel with oxygen which in turn affected the intensity of the flame being directed to the pot.

The surface area of the fuels influenced the size of the combustion surface which was directly reacting with oxygen.

Bulk density of the fuels influenced the burning rates of the test fuels as more dense fuels had less burning rates as compared to those which were less dense which had an effect on the time taken for the water to boil using each fuel.

Arrangement of the fuel in the fuel chamber influenced the primary airflow throughout the entire fuel which affected the combustion properties of the fuel.

\section{CONCLUSIONS AND RECOMMENDATIONS}

\section{Conclusions}

The following conclusions were drawn from the study results;
Pine cones had the lowest time to boil of $9.5 \mathrm{~min}$ utes compared to maize cobs with 12.25 minutes and pinewood with the highest which was 13.25 minutes. Therefore, pine cones boiled water faster than any other test fuel. On the other hand, wood shavings failed to make the water boil. They only raised its temperature to $790 \mathrm{C}$ in 7.5 minutes.

Pinewood had the lowest burning rate of $18 \mathrm{~g} / \mathrm{min}$ compared to other test fuels including pine cones which had the highest which was $27 \mathrm{~g} / \mathrm{min}$. Therefore, pinewood can burn for a longer time than all the other test fuels.

Wood shavings had the lowest specific fuel consumption of $90 \mathrm{~g} /$ liter as compared to pine wood with $101 \mathrm{~g} /$ /iter, maize cobs with $103 \mathrm{~g} /$ liter, and pine cones with the highest which was $107 \mathrm{~g} /$ liter. Therefore, wood shavings used the least grams of fuel per liter of water boiled as compared to other test fuels which required more grams of fuel to boil the same liter of water.

Therefore, according to the experiment results, maize cobs were found to be a better alternative fuel in a gasifier stove use, this is because their time to boil 2.5 liters of water is about 12 minutes, the burning rate is $20 \mathrm{~g} / \mathrm{min}$, the specific fuel consumption was about $104 \mathrm{~g} /$ liter and had the best thermal efficiency of about 33\% with the specific gasifier stove.

\section{Recommendations}

Maize cobs are recommended for use in the gasifier stoves, apart from the scientific evidence, maize cobs have other benefits associated with their wide availability and cheap or no cost since they exist as agricultural wastes, this would help in reducing the pressure on forests for wood fuels like charcoal and firewood.

\section{ACKNOWLEDGMENT}

Mr. Engineer William Bill Powell has been very instrumental in supporting my research both technically and financially. He is passionate about developing the gasifier sector to cub the disadvantages associated with the use of charcoal and its equipment. He heavily funded my research work and gave technical guidance. Thanks to you and your family

I acknowledge Nyabyeya Forestry college staff especially the principal (Mr. Kisakye Richard) for allowing me to research the Biomass Energy Resource and training center, at this center, I was able to 
Table 7. Summary of results and conclusions for T-tests performed on the stove thermal efficiencies for paired test fuels

\begin{tabular}{llll}
\hline Fuels & & T-test P-Value & Significance at 95\% Confidence Level \\
Pine cones & Maize cobs & 0.0000313885 & Yes \\
& Wood shavings & 0.12142691 & No \\
& Pine wood & 0.00100553 & Yes \\
Maize cobs & Pine wood & 0.00000535701 & Yes \\
\hline
\end{tabular}

Table 8. Summary of results and conclusions for T-tests performed on the stove thermal efficiencies for paired test fuels

\begin{tabular}{llll}
\hline & Wood shavings & 0.01125792 & Yes \\
Pine wood & Wood shavings & 0.002081833 & Yes \\
\hline
\end{tabular}

use all the available equipment in the Green charcoal laboratory and workshop to have this research accomplished.

May the almighty GOD reward you all accordingly!

\section{References:}

1. Ariho, D., Tumutegyereize, P. and Bechtel, K. (no date) 'Evaluation of the energy efficiencies of commonly available biomass fuels in Uganda in a “Champion-2008" Top Lit Updraft gasifier stove', p. 10.

2. Biomass for heating | Climate Technology Centre \& Network | Tue, 11/08/2016 (no date a). Available at: https://www.ctc-n.org/technologies/bioma ss-heating (Accessed: 1 December 2021).

3. Biomass for heating | Climate Technology Centre \& Network | Tue, 11/08/2016 (no date b). Available at: https://www.ctc-n.org/technologies/bioma ss-heating (Accessed: 1 December 2021).

4. CREEC, 2011., Centre for Research in Energy and Energy Conservation: Northern Uganda Energy Study report.

5. Household air pollution and health (no date). Available at: https://www.who.int/news-room/fact-s heets/detail/household-air-pollution-and-health (Accessed: 1 December 2021).

6. ISO - Smarter cooking technology for better living(no date).Available at: https://www.iso.org/n ews/isofocus_142-6.html (Accessed: 1 December 2021).

7. MEMD, 2002. Ministry of Energy and Mineral Development: The Energy Policy for Uganda. On line at www.rea.or.ug/userfiles/Energypolicy\%5B\% 5D.pdf, October 2009
8. 'Overview of the Ugandan Energy Sector | Uganda National Renewable Energy \& Energy Efficiency Alliance (UNREEEA)' (no date). Available at: https://unreeea.org/resource-center/overview -of-the-ugandan-energy-sector/ (Accessed: 1 December 2021).

9. Smarter cooking technology for better living(no date) ISO Available at: https://www.is o.org/cms/render/live/en/sites/isoorg/contents /news/2020/09/isofocus142-6.height95pct.html (Accessed: 1 December 2021).

10. Thomson, E. (no date) Uganda-charcoal prices rise, African Review. Available at: http://www .africanreview.com/finance/commodities/ugandacharcoal-prices-rise (Accessed: 1 December 2021).

11. Uganda - World - Consumption - Primary Energy - knoema.com(no date) Knoema. Available at: https://knoema.com//data/uganda+consumpti on+primary-energy/ (Accessed: 1 December 2021). 